\title{
Shaping the landscape of eukaryotic gene expression: horizontal gene transfer
}

Horizontal gene transfer (HGT) in prokaryotes refers to the movement of genes and genetic information between two organisms. This usually results in the spread of antibiotic resistance genes among bacteria. Vertical gene transfer (VGT), on the other hand, refers to the flow of genetic information from parents to offsprings. Until recently, HGT was an exclusive prerogative of the prokaryotes. These are obvious due to the distinct nuclear membrane enclosure of eukaryote genomes that are shielded from outside interferences. VGT can cross species barriers and may even allow the transmission of genes across the kingdoms of life. HGT is now an emerging idea in eukaryotic genomes, challenging previous assertions that HGT is restricted to prokaryotes. It is now accepted that HGT can profoundly influence host metabolic pathways and alter gene expressions even in eukaryotes. HGT, is also fundamentally important during development, origin of human diseases, such as cancer, and neurodegenerative disorders. It may also influence therapeutic outcome by promoting resistant phenotypes. HGT is recently documented in prokaryote to eukaryote HGT is the tardigrade case though an analysis of a draft tardigrade genome suggested that HGT contributed to up to $\sim 17 \%$ of the gene. Further analysis performed after whole genome pair-wise alignments between human genome as well as 53 vertebrate genomes, it was observed that nearly 1500 human genome regions involving 642 known genes, most of which are enriched with ion binding to be conserved with non-mammals than with most mammals. This indicated horizontal gene transfer is more common than we expected in the human genome.

It's a matter of time or maybe a tip of iceberg to know the full extent and implications of HGT. Surprisingly its seems that the eukaryotic genome has many more ways to update itself to vastly expand its repertoire of expression and usability. HGT is just another feather in the crown.

\section{Ruby Dhar ${ }^{1}$, Arun Kumar ${ }^{2 *}$, Subhradip Karmakar ${ }^{3 *}$ \\ ${ }^{1}$ Scientist, Room No-3020 Department of Biochemistry, All India Institute of Medical Sciences, New Delhi, India. \\ ${ }^{2}$ Professor and Head, Department of Biochemistry, Jagannath \\ Gupta Institute of Medical Sciences and Hospital, Budge Budge, Kolkata, India ${ }^{3}$ Associate-Professor, Room No-3020, Department of Biochemistry, All India Institute of Medical Sciences, New Delhi, India.}

Access this article online

Website:

http://nepjol.info/index.php/AJMS

DOI:10.3126/ajms.v12i10.39643

E-ISSN: 2091-0576

P-ISSN: 2467-9100

Copyright (c) 2021 Asian Journal of Medical Sciences

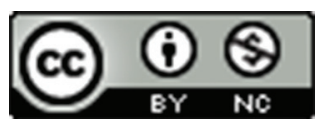

This work is licensed under a Creative Commons Attribution-NonCommercial 4.0 International License.

Address for Correspondence: Dr. Arun Kumar, Professor and Head, Department of Biochemistry, Jagannath Gupta Institute of Medical Sciences and Hospital, Budge Budge, Kolkata, India. Mobile: +91-7584089886. Email: arun732003@gmail.com Dr. Subhradip Karmakar, Associate Professor, Department of Biochemistry, Room 3020, All India Institute of Medical Sciences, New Delhi, India. Mobile: +919999612564.

E-mail: subhradip.k@aiims.edu

\section{REFERENCES}

1. Huang W, Tsai L, Li Y, Hua N, Sun C and Wei C. Widespread of horizontal gene transfer in the human genome. BMC Genomics. 2017;18(1):274.

https://doi.org/10.1186/s12864-017-3649-y

2. Danchin EGJ. Lateral gene transfer in eukaryotes: tip of the iceberg or of the ice cube?. BMC Biol. 2016; 14: 101.

https://doi.org/10.1186/s12915-016-0330-x

3. Emamalipour M, Seidi K, Zununi Vahed S, Jahanban-Esfahlan A, Jaymand M, Majdi $H$, et al. Horizontal Gene Transfer: From Evolutionary Flexibility to Disease Progression. Front Cell Dev Biol. 2020; 8:229.

https://doi.org/10.3389/fcell.2020.00229

4. Soucy SM, Huang J and Gogarten JP. Horizontal gene transfer: building the web of life. Nat Rev Genet. 2015;16(8):472-482.

https://doi.org/10.1038/nrg3962

5. Tiwari $P$ and Bae H. Horizontal Gene Transfer and Endophytes: An Implication for the Acquisition of Novel Traits. Plants (Basel). 2020;9(3):305.

https://doi.org/10.3390/plants9030305 
Authors Contribution:

All authors contributed equally towards scripting of this editorial.

Work attributed to:

All India Institute of Medical Sciences, New Delhi, India.

Orcid ID:

Dr. Ruby Dhar - iD https://orcid.org/0000-0003-3600-6554

Dr. Arun Kumar - (1) https://orcid.org/0000-0002-8800-0296

Dr. Subhradip Karmakar - (iD https://orcid.org/0000-0002-4757-8729

Source of Funding: None, Conflict of Interest: None declared 